\title{
ASSOCIATION BETWEEN PTSD SYMPTOMS AND STRESS- RELATED FACTORS AMONG NUCLEAR EMERGENCY WORKERS OVER A LONG PERIOD
}

\author{
H. Hiro' ${ }^{1}$ A. Hino ${ }^{1}$, K. Mafune 1 , A. Inoue ${ }^{2}$, J. Shigemura ${ }^{3}$, M. Yamada 4 , T. Ookubo ${ }^{5}$ \\ 1 University of Occupational and Environmental Health, Japan, Department of Mental Health, Kitakyushu, Japan \\ 2 Kitasato University School of Medicine, Department of Public Health, Sagamihara, Japan \\ 3 National Defense Medical College, Department of Psychiatry, Tokorozawa, Japan \\ 4 Radiation Effects Research Foundation, Hiroshima, Japan \\ 5 National Institute of Occupational Safety and Health, Japan, Kawasaki, Japan
}

\section{Introduction}

The Fukushima Daiichi Nuclear Power Plant (NPP) suffered serious damage from the Great East Japan Earthquake and Tsunami of 2011.

The Ministry of Health, Labour and Welfare of Japan (MHLW) temporarily raised the emergency cumulative radiation exposure dose limit in Fukushima NPP from 100 millisievert (mSv) to 250 mSv during the period from March 14 to December 16, 2011. About 20,000 workers were involved in the emergency work for coping with accidents during this period.

\section{Objectives:}

This study examined the association between PTSD symptoms and stress-related factors among nuclear emergency workers 68 years after the disaster.

\section{Subjects and Methods:}

All of the workers engaged at Fukushima NPP from March 14 to December 16, 2011 were registered as emergency workers by MHLW. All the emergency workers $(\mathrm{N}=19,808)$ were recruited through individual letters from the authors since January 2015. The survey, using a self-administered questionnaire, was conducted on those who agreed to participate in an epidemiological study on the emergency workers for the TEPCO Fukushima Daiichi Nuclear Power Plant accident (Nuclear Emergency Workers Study) and underwent medical examination by December $2018(\mathrm{~N}=4,979)$. The participants completed and sent the questionnaire to the authors.

All participants were assured that their participation was voluntary.

PTSD symptoms were measured using IES-R (Impact of Events Scale - Revised). The stress-related factors we evaluated included life events, stress coping (BSCP), sense of coherence (SOC-UTHS), self-esteem (by Rosenberg), generalized selfefficacy (by Sherer), resilience (CD-RISC2), social support (current/emergency), satisfaction (life/job), and stigmaassociated stress owing to post-disaster management criticism (slanderous defamation). Multiple regression analysis was performed with the IES-R score as the dependent variable and stress-related factors as the independent variables.

\begin{tabular}{|c|c|c|c|}
\hline \multicolumn{4}{|c|}{ Demographic and occupational characteristics of the subjects } \\
\hline & $N(\%)$ & & $\mathrm{N}(\%)$ \\
\hline Age & 3784 & \multicolumn{2}{|c|}{ Timing of engaging in emergency work } \\
\hline$\leq 29$ & $61(1.6)$ & March-May & $2226(60.6)$ \\
\hline $30-39$ & $371(9.8)$ & June-July & $652(17.8)$ \\
\hline $40-49$ & $1059(28.0)$ & August-September & $333(9.1)$ \\
\hline $50-59$ & $1269(33.5)$ & October-December & $285(7.8)$ \\
\hline$\geq 60$ & $1024(27.1)$ & January- & $176(4.8)$ \\
\hline \multicolumn{2}{|l|}{ Marital status } & \multicolumn{2}{|l|}{ Working period } \\
\hline Never married & $374(9.9)$ & $\leq 5$ days & $1170(31.3)$ \\
\hline Currently married & $3177(84.2)$ & $\leq 10$ days & $409(11.0)$ \\
\hline Divorced & $172(4.6)$ & $\leq 30$ days & $614(16.4)$ \\
\hline Widowed & $46(1.2)$ & $\leq 100$ days & $576(15.4)$ \\
\hline Others & $2(0.1)$ & $\geq 101$ days & $966(25.9)$ \\
\hline \multicolumn{4}{|l|}{ Education } \\
\hline $\begin{array}{l}\text { Middle school or less } \\
\text { High school }\end{array}$ & $\begin{array}{c}265(7.0) \\
1654(43.7)\end{array}$ & Engineering and construct & $782(65.1)$ \\
\hline Vocational school & $190(5.0)$ & Reactor control & $792(68.6)$ \\
\hline Some college & $211(5.6)$ & Dose control & $286(65.1)$ \\
\hline College & $1000(26.4)$ & Material management & $112(24.0)$ \\
\hline Graduate school & $434(11.5)$ & Others & $1802(75.6)$ \\
\hline Others & $30(0.8)$ & & \\
\hline
\end{tabular}

Funding: This study was supported by the Industrial Disease Clinical Research Grant (No.14090101) from the Ministry of Health, Labour and Welfare (Japan).

\section{Results and Conclusions:}

In total, 3,784 nuclear emergency workers completed a selfadministered questionnaire, of which 3,776 were male.

The IES-R score was significantly higher in the workers who had worked on-site for a long period of time. It was also associated with scores of life events, stress coping, sense of coherence, self-esteem, self-efficacy, social support, and slanderous defamation. Life events and slanderous defamation scores had particularly strong associations with the IES-R score.

Long-term follow-up is necessary for nuclear emergency workers who worked for a longer period of time, and mitigating slanderous defamation responses is one of the most important measures to support the mental health of these workers.

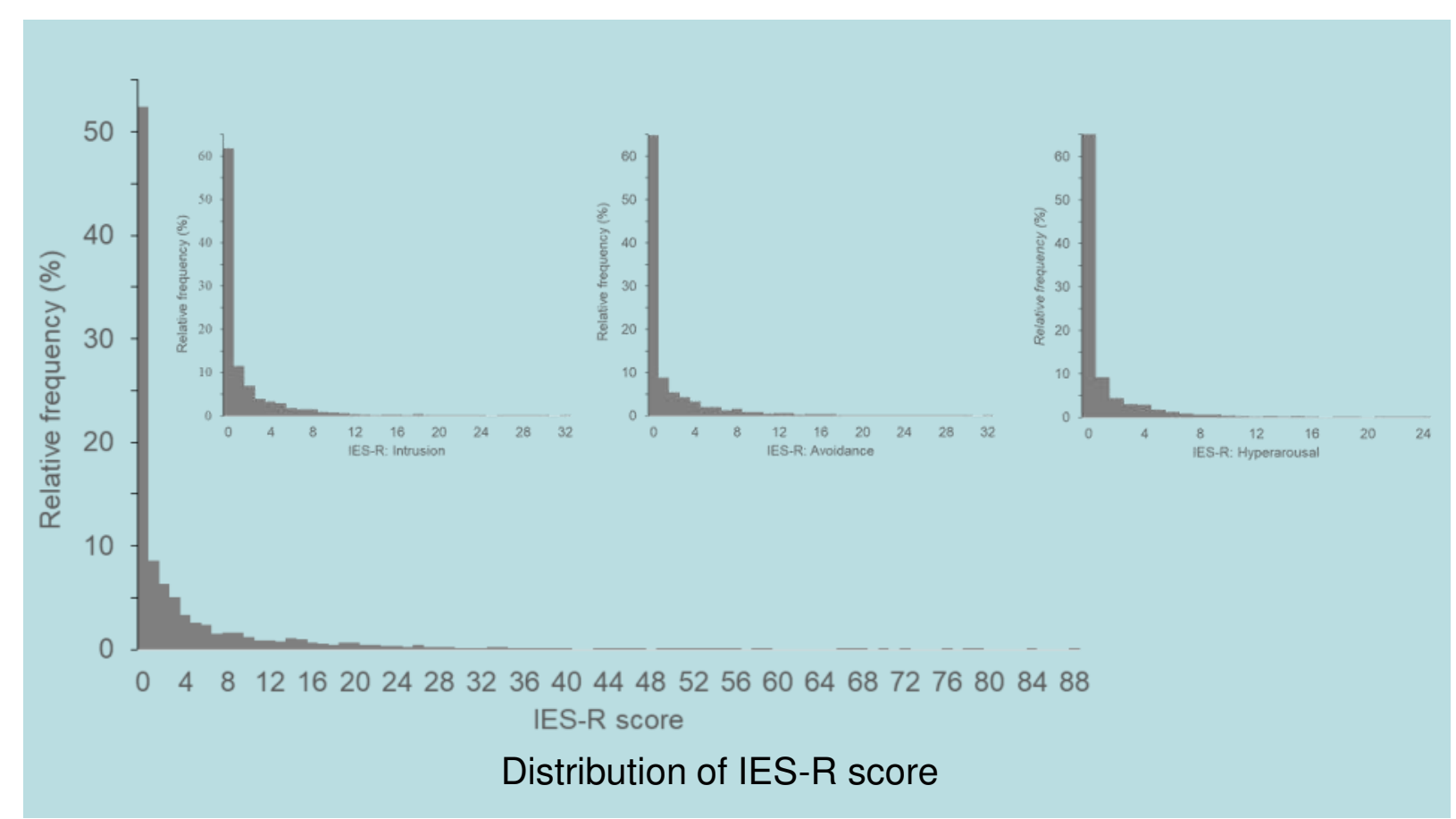

Association between IES-R score and stress-related factors in the subjects (Results of multiple regression analysis)

\begin{tabular}{llccccc}
\hline & & $\mathrm{b}$ & $95 \% \mathrm{Cl}$ & $\mathrm{p}$ & $\beta$ & $\mathrm{VIF}$ \\
\hline Slanderous defamation & & .896 & $.854-.938$ & .000 & .589 & 1.17 \\
Support(Current) & Supervisor & -.365 & $-.567--.163$ & .000 & -.096 & 4.37 \\
& Coworker & .136 & $-.083-.356$ & .223 & .034 & 4.50 \\
& Private & -.191 & $-.348--.034$ & .017 & -.045 & 2.09 \\
Support(Emergency) & Supervisor & .030 & $-.173-.233$ & .771 & .009 & 5.19 \\
& Coworker & -.241 & $-.461--.021$ & .032 & -.065 & 5.32 \\
& Private & .135 & $.010-.261$ & .035 & .039 & 2.00 \\
Life event & & .955 & $.702-1.207$ & .000 & .105 & 1.19 \\
BSCP & Active solusion & .081 & $-.054-.215$ & .239 & .020 & 1.77 \\
& Seeking help for solution & -.140 & $-.257--.022$ & .020 & -.041 & 1.80 \\
& Changing a point of view & .168 & $.069-.266$ & .001 & .048 & 1.23 \\
& Emotional expression involving others & .330 & $.138-.522$ & .001 & .049 & 1.23 \\
& Avoidance and suppression & -.101 & $-.247-.045$ & .176 & -.022 & 1.59 \\
SOC3-UTHS & Changing mood & .085 & $-.034-.205$ & .162 & .021 & 1.37 \\
Self-esteem & & -.122 & $-.220--.024$ & .015 & -.042 & 1.74 \\
Self-efficacy & -.077 & $-.125--.030$ & .001 & -.060 & 2.06 \\
CD-RISC2 & & .050 & $.022-.079$ & .000 & .073 & 2.53 \\
Satisfaction(life, job) & -.120 & $-.309-.069$ & .212 & -.022 & 1.81 \\
Adjusted R & & -.022 & $-.238-.195$ & .843 & -.003 & 1.64 \\
& & .480 & & & & \\
\hline
\end{tabular}

The Nuclear Emergency Workers Study Group includes Toshiteru Okubo (Radiation Effects Research Foundation; RERF) as the principal investigator, Makoto Akashi (National Institutes for Quantum and Radiological Science and Technology; NIQRST), Hisanori Hiro (University of Occupational and Environmental Health UOEH), Hokuto Hoshi (Hoshi General Hospital), Fumiyoshi Kasagi (Radiation Effects Association), Kazuaki Kawai (UOEH), Hiroko Kitamura (RERF), Kazunori Kodama (RERF), Osamu Kurihara (NIQRST), Megumi Miyagawa (Toranomon Hospital), Takuma Momose (Japan Atomic Energy Agency), Waka Ohishi (RERF), Ryuji Okazaki (UOEH), Kotaro Ozasa (RERF), Hiroshi Sasaki (Kanazawa Medical University), Jun Shigemura (National Defense Medical College), Tomotaka Sobue (Osaka University), Yumiko Suto (NIQRST), Nobuyuki Taniguchi (Jichi Medical University), and Shinji Yoshinaga (NIQRST) as the investigators. 